Int. J. Electrochem. Sci., 14 (2019) 7232 - 7240

\title{
In situ Fabrication of Copper Nanocubes with Platinum Skin on 3D Graphene-Carbon Nanotubes Hybrid for Efficient Methanol Electrooxidation
}

\author{
Genping Yi, Ziwen Chang, Guangzhen Liu, Liming Yang*
}

Key Laboratory of Jiangxi Province for Persistent Pollutants Control and Resources Recycle, Nanchang Hangkong University, Nanchang 330063, P. R. China

*E-mail: yangliming0809185@126.com (L. M. Yang)

doi: $10.20964 / 2019.08 .25$

Received: 7 November 2017 / Accepted: 19 March 2019 / Published: 30 June 2017

Tuning the macro-morphology and micro-structure simultaneously of platinum (Pt)-based electrocatalysts is pivotal for enhancing catalytic performance, but still remains great challenge. Herein, we first report elaborate copper nanocubes with Pt skin on 3D reduced graphene oxide-carbon nanotubes (rGO@CNTs) support. Graphene oxide is used as a surfactant to disperse pristine CNTs with a little $\mathrm{CuSO}_{4}$ for electrochemical preparation of macro-morphological rGO@CNTs supporting $\mathrm{Cu}$ nanocubes, and subsequently reacted with $\mathrm{H}_{2} \mathrm{PtCl}_{6}$ solution via galvanic replacement to realize $\mathrm{Pt}$ skin micro-structure. Cyclic voltammetry and chronoamperometry technique indicate that the resultant $\mathrm{Pt}-\mathrm{Cu} / \mathrm{rGO} @ \mathrm{CNT}$ catalyst is equipped with outstanding electrocatalytic activity and stability towards methanol oxidation reaction.

Keywords: Graphene; Carbon nanotubes; $\mathrm{Cu}$ nanocubes; Pt skin; Electrodeposition; Energy storage and conversion

\section{FULL TEXT}

(C) 2019 The Authors. Published by ESG (www.electrochemsci.org). This article is an open access article distributed under the terms and conditions of the Creative Commons Attribution license (http://creativecommons.org/licenses/by/4.0/). 